\title{
Association between periodontal disease and coronary heart disease risk in Chinese population: evidence from a meta- analysis
}

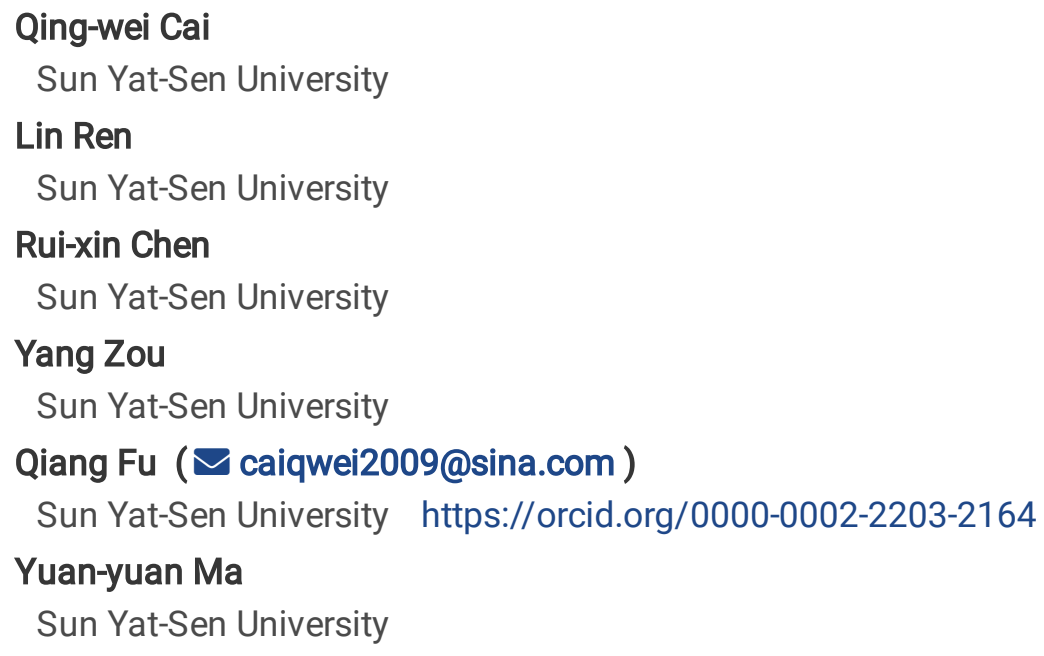




\section{Abstract}

Aims More and more research is focused on studying the relationship of periodontal disease with susceptibility to coronary heart disease (CHD), among which discrepancies have risen. The current study aimed to evaluate the possible relationship about periodontal disease and CHD in certain Chinese population. Methods The PubMed, Embase, Web of Science, the Cochrane Library, the Chinese Biomedical Database, and the Chinese National Knowledge Infrastructure were searched up to December 2018. The overall and subgroup analyses were performed using fixed or random-effect model depending on heterogeneity. Results A total of 2241 CHD cases and 2160 in 15 studies were used in the current study. Overall, a significantly elevated relationship about periodontal disease on CHD risk was found in all included Chinese subjects $(\mathrm{OR}=3.04,95 \% \mathrm{Cl}, 2.37-3.92)$. Subgroup analyses by geographic location and sources of control were also performed; all the results in subgroup analyses were consistent with the overall result. Meanwhile, the significant association was found among the measures of periodontal disease with attachment loss, periodontal index, two or more clinical indications, and gum recession as well as CHD assessment method with WHO criteria and coronary arteriongraphy. Conclusions Collectively, the meta-analysis indicated that periodontal disease was capable of causing CHD susceptibility among Chinese.

\section{Introduction}

At present, cardiovascular disease accounts for $30 \%$ of all deaths worldwide. Moreover, the great majority of this disease burden is currently occurred in developing countries [1]. The death of coronary heart disease (CHD) dropped significantly in United States after peaking around 1968 [2]. But, CHD had become a public health problem during the past few decades in China. The mortality rate of CHD (every 100000 people per year) in China has risen from 95.3 in 1999 to 103.4 in 2008 [3]. In 2008, the crude incidence rate of ischemic heart disease in Chinese urban inhabitants was $12.7 \%$ [4]. Although some factors which may affect the risk of CHD had been explored, a large proportion of CHD has not been explained by the traditional risk factor. In the recent publications, several evidences had involved the cause of chronic inflammation in CHD [5]. Interestingly, periodontal disease had been studied to be related with exaltation of several markers of chronic inflammation, therefore, we assumed an etiologic association about periodontal disease on CHD risk. The association about periodontal disease on CHD risk had been studied since a century ago, and many systematic reviews and metaanalyses had assessed the potential association of periodontal disease with the increased risk of CHD [6-14]. Although a large amount of evidence was showed, a scientific statement declaration by the American Heart Association in 2012 expounded that it has not enough evidence to determine the causal-related association about periodontal disease on the risk of heart disease [15]. It was still unclear whether this relationship differs among people from different race backgrounds. Therefore, the current study employed a meta-analysis to quantitatively clarify the association about periodontal disease on CHD risk based on included Chinese population.

\section{Materials And Methods}

\section{Identification of eligible studies}

Meta-analysis was conducted according to the guidelines of the PRISMA group. Search scopes included articles from PubMed, Embase, Web of Science, the Cochrane Library, the Chinese Biomedical Database [CBM], and the Chinese National Knowledge Infrastructure [CNKI] databases published until December 2018. The search keywords were ("coronary heart disease"OR "coronary disease"OR "heart disease"OR "ischemic heart disease"OR "myocardial infarction") AND ("periodontal disease"OR "periodontitis") AND ("China" OR "Chinese") . No language limitation was applied. To available identify relevant studies; we also manually search for references cited in the eligible articles. A study should be included if it met all the following criteria: (1) it was a case-control study to investigate the association about periodontal disease on CHD risk; (2) it provided odds ratios (ORs) and 95\% confidence intervals (Cls); (3) it evaluated the population in Chinese; (4) the study which had the most complete data was used if two or more studies had partial overlaps. The study was excluded if it was review, letter, case report, and editorial article. 


\section{Data extraction}

We filtered the titles and abstracts of all possible related papers to identify their relevancy. The full paper would be reviewed if it cannot be sure depending on the title and abstract. Information from all eligible publications was independently extracted with two investigators. The following data were extracted: first author's name; publication years; geographic location; sources of control; number of participants; and measures of periodontal disease. Sources of control were divided into hospital-based or population-based studies. The following measures for periodontal disease in dental examinations were: periodontal index, gum bleeding, attachment loss, gum recession, teeth loosening, inflammation/gingivitis, and tooth loss.

\section{Statistical analysis}

The pooled results about periodontal disease on CHD risk were calculated by ORs with $95 \% \mathrm{Cls}$. Z test was adopted to explore whether the pooled ORs were significant. Regarding potential heterogeneity among studies, which assessed by Cochran's Q-statistic, we defined significant heterogeneity at the levels $P<0.10$. A random-effect model was used on the analyses when significant heterogeneity was observed, otherwise fixed-effect model was used. Sensitivity analysis was carried out by compared the results of fixed-effect model with random-effect model. Egger's test was used to detect the publication bias. Our meta-analysis was calculated by Stata 12.0 (College Station, TX, USA); $p<0.05$ was known as significant. In addition, subgroup analyses by geographic location and source of controls to further explore the association about periodontal disease on CHD risk. Furthermore, we pooled the ORs about dental and CHD respectively if they assessed the periodontal disease differently to explore influence of the measures.

\section{Results}

\section{Research characteristics}

One hundred and eighty-eight articles which evaluated the association about periodontal disease on CHD risk were searched. At last, fifteen articles [16-30] were included in our final analysis. All the eligible articles were published between 2001 and 2017. Figure 1 shows the flowchart of included or excluded reason. Totally, there were 2241 CHD cases and 2160 controls involved in our analysis, which were included to assess the potential association about periodontal disease on CHD risk in Chinese. The characteristics of each individual article are presented in Table 1.

\section{Meta-analysis results}

In the results of the overall analysis, periodontal disease could significantly increase the risk of $\mathrm{CHD}(\mathrm{ORs}=3.04,95 \% \mathrm{Cl}=$ 2.37-3.92; Figure 2). Meanwhile, the heterogeneity was detected significantly $\left(I^{2}=69.8 \%, p<0.001\right)$. Detailed results summarized in table 2 found that all the results in subgroup analyses were consistent with the overall analysis, suggesting no single factor had essential impact on the whole result. Furthermore, subgroup analysis was also performed to explore the sources of heterogeneity. The further subgroup study by geographic location and source of controls suggested that significant association was found in northern and southern of China, as well as population-based studies and hospitalbased studies.

Some articles had explained the categories for dental examinations and CHD assessment method, as follows: attachment loss; periodontal index; two or more clinical indications; gum recession; alveolar bone loss; WHO criteria and coronary arteriongraphy. The significant association was found among the measures of periodontal disease with attachment loss, periodontal index, two or more clinical indications, and gum recession as well as CHD assessment method with WHO 
criteria and coronary arteriongraphy (Table 2). However, there was non-significant association was found in the dental assessment method with alveolar bone loss.

\section{Sensitivity analysis and publication bias}

Sensitivity analysis which described in the methods was performed. All the pooled ORs were significantly both in the total and subgroup analyses. Hence, results of the sensitivity analysis suggested that the results in the current study were relatively stable (Table 2). Publication bias was detected by Begg's funnel plot and Egger's test. As shown in Figure 3, funnel plot indicated that the shape was symmetrical. At the same time, the Egger's test $(t=3.21, P=0.007$; Figure 4$)$ did not detect any publication bias.

\section{Discussion}

The associations about periodontal disease on both $\mathrm{CHD}$ and cardiovascular disease risk have been explored for many years. These diseases appear to have a number of characteristics in common such as high incidence in older persons, smokers and hypertensive patients etc [31]. Since periodontal disease and CHD are common, quantifying their association is of significant public health importance [9]. Our study assessing the association about periodontal disease, including attachment loss, periodontal index, gum recession, and alveolar bone loss, suggested that periodontal disease could be significantly increased the risk of CHD in Chinese. These analyses also provided the currently assessment of the relationship about periodontal disease on CHD risk. The present meta-analysis was carried out to clarify the effects for Chinese only and therefore to reduce the influence of different geographic location background or lifestyle.

Our meta-analysis used 15 studies involving $2241 \mathrm{CHD}$ cases and 2160 controls. Pooled results from the study suggested that periodontal disease cases had an overall 3.04-fold increased risk of CHD when compared to those with no periodontal disease or the general people in China. Subgroup analyses were also conducted to further explore the effective of geographic location and sources of control. Significant association was also found about periodontal disease on CHD risk in northern and southern of China, as well as studies with hospital-based controls and population-based controls. In addition, the significant association was found among the measures of periodontal disease with attachment loss, periodontal index, two or more clinical indications, and gum recession as well as CHD assessment method with WHO criteria and coronary arteriongraphy.

There have been several published meta-analyses which reflected that periodontal disease may contribute to the risk of CHD [6-14]. It is obvious lack of standardized protocols for determining periodontal disease and CHD. Some research used self-report, which may underestimate the level of disease, while other studies including gingivitis and periodontitis may overestimate disease prevalence. Thus, this point should be addressed with a meta-analysis in order to reach a consensus. On the other hand, we only included Chinese population with relatively consistent evaluation criteria for periodontal disease and CHD, and conducting subgroup analyses by geographic location and source of controls. Two more databases (CBM and $\mathrm{CNKI}$ ) in Chinese language were searched and more Chinese participants included in our study than the previous metaanalyses. Furthermore, the pooled OR about the association of periodontal disease on CHD risk in our study was higher than those published meat-analyses with populations except Chinese. Sensitivity analysis confirmed the reliability and stability of this study. Thus, findings from the present paper strongly supported that periodontal disease could significantly increase CHD risk in Chinese.

Some limitations existed in our study should be attention. Firstly, a publication bias has been indicated in our study, as all included studies were positive results and they may be easier to publish. Secondly, the subgroup analyses by aging, cigarette smoking, alcohol consumption, and dietary structure were not performed because there was no enough information in each individual study. Thirdly, CHD is a complex disease with multiple factors, containing environmental and genetic factors. However, some studies in our meta-analysis didn't consider the effects of environmental factors on CHD. 
In conclusion, the meta-analysis indicated that periodontal disease was capable of causing CHD susceptibility among Chinese. While some limitations exited in the current paper, more studies with large participants of different background are warranted to validate this association reported in our analysis. It is recommendation to prevent the heart disease with the maintenance of periodontal health due to the high mortality rate of cardiovascular diseases and the relatively minor morbidity of periodontal therapy.

\section{Abbreviations}

CHD: coronary heart disease; OR: odds ratio; Cl: confidence interval; CBM: Chinese Biomedical Database; CNKI: Chinese National Knowledge Infrastructure; HC: hospital control; PC: healthy population control.

\section{Declarations}

\section{Acknowledgment}

None

\section{Funding}

National Natural Science Foundation of China (Grant No. 81570955)

\section{Availability of data and materials}

All data are included in the study.

\section{Authors' contributions}

Qiang Fu and Yuan-yuan Ma designed the paper. Lin Ren, Rui-xin Chenand Yang Zou collected and analyzed the data. Qingwei Cai drafted the manuscript and all the authors approved submission.

\section{Competing interests}

The author reports no conflicts of interest.

\section{Consent for publication}

Not applicable

\section{Ethics approval and consent to participate}

Not applicable

\section{References}

[1] Gaziano TA. Cardiovascular disease in the developing world and its cost-effective management. Circulation. 2005;112:3547-53. 
[2] Rosamond W, Flegal K, Friday G, Furie K, Go A, Greenlund K, et al. Heart disease and stroke statistics-2007 update: a report from the American Heart Association Statistics Committee and Stroke Statistics Subcommittee. Circulation. 2007;115:e69-171.

[3] Jiang G, Wang D, Li W, Pan Y, Zheng W, Zhang H, et al. Coronary heart disease mortality in China: age, gender, and urbanrural gaps during epidemiological transition. Rev Panam Salud Publica. 2012;31:317-324.

[4] Li X, Zhang Y, Wang M, Lv X, Su D, Li Z, Ding D, Xia M, Qiu J, Hu G, Ling W. The prevalence and awareness of cardiometabolic risk factors in Southern Chinese population with coronary artery disease. ScientificWorldJournal. 2013;2013:416192.

[5] Ridker PM, Hennekens CH, Buring JE, Rifai N. C-reactive protein and other markers of inflammation in the prediction of cardiovascular disease in women. N Eng J Med. 2000;342:836-43.

[6] Madianos PN, Bobetsis GA, Kinane DF. Is periodontitis associated with an increased risk of coronary heart disease and preterm and/or low birth weight births? J Clin Periodontol. 2002;29:22-36; discussion 37-8.

[7] Janket SJ, Baird AE, Chuang SK, Jones JA.Meta-analysis of periodontal disease and risk of coronary heart disease and stroke. Oral Surg Oral Med Oral Pathol Oral Radiol Endod. 2003;95:559-69.

[8] Scannapieco FA, Bush RB, Paju S. Associations between periodontal disease and risk for atherosclerosis, cardiovascular disease, and stroke. A systematic review. Ann Periodontol. 2003;8:38-53.

[9] Khader YS, Albashaireh ZS, Alomari MA. Periodontal diseases and the risk of coronary heart and cerebrovascular diseases: a meta-analysis. J Periodontol. 2004;75:1046-53.

[10] Bahekar AA, Singh S, Saha S, Molnar J, Arora R.The prevalence and incidence of coronary heart disease is significantly increased in periodontitis: a meta-analysis.Am Heart J. 2007;154:830-7.

[11] Mustapha IZ, Debrey S, Oladubu M, Ugarte R.Markers of systemic bacterial exposure in periodontal disease and cardiovascular disease risk: a systematic review and meta-analysis. J Periodontol. 2007;78:2289-302.

[12] Humphrey LL, Fu R, Buckley DI, Freeman M, Helfand M. Periodontal disease and coronary heart disease incidence: a systematic review and meta-analysis. J Gen Intern Med. 2008;23:2079-86.

[13] Blaizot A, Vergnes JN, Nuwwareh S, Amar J, Sixou M. Periodontal diseases and cardiovascular events: meta-analysis of observational studies. Int Dent J. 2009;59:197-209.

[14] Leng WD, Zeng XT, Kwong JS, Hua XP. Periodontal disease and risk of coronary heart disease: An updated metaanalysis of prospective cohort studies. Int J Cardiol. 2015;201:469-72.

[15] Lockhart PB, Bolger AF, Papapanou PN, Osinbowale O, Trevisan M, Levison ME, et al. Periodontal disease and atherosclerotic vascular disease: does the evidence support an independent association?: a scientific statement from the American Heart Association.Circulation. 2012;125:2520-44.

[16] Chen WL, Yan Y, Wang QY. Relationship between the changes of serum C- reactive protein in patients with coronary heart disease and periodontal disease. Chinese General Practice 2001; 4:859-860. (article in Chinese)

[17] Lin YG, Li WL. Assessing the relationship between periodotal infection and coronary heart disease in elderly people. J Clin Stomatol 2001; 17:15-16. (article in Chinese) 
[18] Liu CL. Clinical observation of chronic periodontitis and coronary heart disease. J Modern Stomatol 2003; 17:374-375. (article in Chinese)

[19] Huang HM, Wang QT, Yan SP. A clinical questionnaire about the relationship between the periodontal disease and coronary heart disease. Chin J Conserv Dent 2003; 13: 218-221. (article in Chinese)

[20] Tang LY, Huang W. Study on the relationship between periodontal disease and coronary heart disease. Acta Medicinae Sinica 2004; 17:959-60. (article in Chinese)

[21] Liu P, Zhang Y, Wang SJ, Zhang FH, Zheng PH. Correlation between periodontal disease and coronary atherosclerotic heart disease. Zhongguo Yi Xue Ke Xue Yuan Xue Bao. 2006;28:169-72. (article in Chinese)

[22] Zhang YM, Zhong LJ, He BX, Nie J, Wang X, Li WC. Study on the correlation between coronary heart disease and chronic periodontitis.Zhonghua Liu Xing Bing Xue Za Zhi. 2006 ;27:256-9.

[23] Zhang DJ, Liu H, Zhao XZ. Research of the relationship between the periodontal and coronary heart disease. Chin J Conserv Dent 2006; 16: 38-40. (article in Chinese)

[24] Li GZ, Xu L, Quan ZL, Kou Z, Cai L, Su L, Li X, Zhong X. Study on the correlation between periodontal disease and coronary heart disease in the elderly: a report of 662 cases. J South Med Univ 2006; 26: 1652-'654. (article in Chinese)

[25] Meng PS, Wei ZM, Bai XF, Li ZQ. Research of the relationship between the periodontal disease and coronary heart disease. Chin J Med Guide 2008; 10: 486-487. (article in Chinese)

[26] Wu ZZ, Yao XL. Study on the relationship between periodontal disease and coronary atherosclerotic heart disease. Modern Med J 2008; 36:185-187. (article in Chinese)

[27] Dong LW, Xing CY, Wang XH, Huang W. Research of the relationship between the periodontal disease and coronary heart disease. J Dental Prev Treat 2009; 17:357-361. (article in Chinese)

[28] Chen JX. Investigation and analysis of the correlation between coronary heart disease and periodontitis. Chinese Community Doctors 2011; 13:163. (article in Chinese)

[29] Zhang LP, Li XQ, Zhou GX, Fan HM. Periodontal disease was an independent risk factor of coronary heart disease by multi-factors Logistic regression analysis. Clinical Medicine of China 2012; 28:284-286. (article in Chinese)

[30] Lu YZ, Fan B, Cao XY, Wang LS. Clinical study on the relationship between periodontal disease and coronary heart disease. Journal of Nantong University (Medical Sciences ) 2017; 37: 565-567. (article in Chinese)

[31] Beck JD, Slade G, Offenbacher S. Oral disease, cardiovascular disease and systemic inflammation. Periodontol 2000. 2000; 23:110-20.

\section{Tables}

Table 1. Characteristics of studies included in the meta-analysis 


\begin{tabular}{|c|c|c|c|c|c|c|c|c|c|}
\hline References & Geographic & Sources & CHD & Control & CHD & Cases & Cont & trols & $\begin{array}{ll}\text { Dental } & \text { CHD }\end{array}$ \\
\hline & areas & $\begin{array}{l}\text { of } \\
\text { control }\end{array}$ & $\begin{array}{l}\text { Case } \\
\text { number }\end{array}$ & number & $\begin{array}{l}\text { Periodontal } \\
\text { disease }\end{array}$ & $\begin{array}{c}\text { No } \\
\text { periodontal } \\
\text { disease }\end{array}$ & $\begin{array}{l}\text { Periodontal } \\
\text { disease }\end{array}$ & $\begin{array}{c}\text { No } \\
\text { periodontal } \\
\text { disease }\end{array}$ & $\begin{array}{l}\text { assessment assessment } \\
\text { method method }\end{array}$ \\
\hline Chen 2001 & Guangdong & PC & 40 & 40 & 33 & 7 & 10 & 30 & $\begin{array}{l}\text { attachment WHO criteria } \\
\text { loss }\end{array}$ \\
\hline Lin 2001 & Beijing & $\mathrm{HC}$ & 88 & 128 & 47 & 41 & 49 & 79 & $\begin{array}{l}\text { periodontal WHO criteria } \\
\text { index }\end{array}$ \\
\hline Liu 2003 & Tianjin & PC & 216 & 216 & 92 & 124 & 26 & 190 & $\begin{array}{c}\text { periodontal coronary } \\
\text { index }\end{array}$ \\
\hline $\begin{array}{l}\text { Huang } \\
2003\end{array}$ & Shaanxi & $\mathrm{HC}$ & 146 & 136 & 76 & 70 & 44 & 92 & $\begin{array}{l}\text { two or more coronary } \\
\text { clinical arteriongraphy } \\
\text { indications }\end{array}$ \\
\hline Tang 2004 & Guangxi & $\mathrm{HC}$ & 250 & 250 & 156 & 94 & 115 & 135 & $\begin{array}{c}\text { periodontal } \\
\text { index }\end{array}$ \\
\hline Liu 2006 & Shandong & $\mathrm{HC}$ & 45 & 40 & 36 & 9 & 19 & 21 & $\begin{array}{l}\text { periodontal WHO criteria } \\
\text { index }\end{array}$ \\
\hline $\begin{array}{l}\text { Zhang } \\
2006\end{array}$ & Xinjiang & $\mathrm{HC}$ & 277 & 238 & 152 & 125 & 71 & 167 & $\begin{array}{c}\text { attachment coronary } \\
\text { loss arteriongraphy }\end{array}$ \\
\hline $\begin{array}{l}\text { Zhang } \\
2006 a\end{array}$ & Shandong & $\mathrm{HC}$ & 76 & 74 & 40 & 36 & 25 & 49 & $\begin{array}{c}\text { attachment coronary } \\
\text { loss arteriongraphy }\end{array}$ \\
\hline Li 2006 & Shaanxi & $\mathrm{HC}$ & 357 & 305 & 307 & 50 & 220 & 85 & $\begin{array}{c}\text { periodontal coronary } \\
\text { index arteriongraphy }\end{array}$ \\
\hline $\begin{array}{l}\text { Meng } \\
2008\end{array}$ & Heilongjiang & PC & 150 & 150 & 87 & 63 & 49 & 101 & $\begin{array}{l}\text { gum } \\
\text { recession }\end{array}$ \\
\hline Wu 2008 & Hunan & $\mathrm{HC}$ & 77 & 75 & 65 & 12 & 26 & 49 & $\begin{array}{cc}\text { gum } & \text { coronary } \\
\text { recession } & \text { arteriongraphy }\end{array}$ \\
\hline Dong 2009 & Guangdong & PC & 161 & 162 & 122 & 39 & 97 & 65 & $\begin{array}{c}\text { alveolar coronary } \\
\text { bone loss arteriongraphy }\end{array}$ \\
\hline Chen 2011 & Guangdong & $\mathrm{HC}$ & 46 & 34 & 37 & 9 & 10 & 24 & $\begin{array}{c}\text { alveolar coronary } \\
\text { bone loss arteriongraphy }\end{array}$ \\
\hline $\begin{array}{l}\text { Zhang } \\
2012\end{array}$ & Hebei & $\mathrm{HC}$ & 162 & 162 & 110 & 52 & 89 & 73 & $\begin{array}{cc}\text { gum } & \text { coronary } \\
\text { recession } & \text { arteriongraphy }\end{array}$ \\
\hline Lu 2017 & Jiangsu & $\mathrm{HC}$ & 150 & 150 & 126 & 24 & 96 & 54 & $\begin{array}{l}\text { two or more coronary } \\
\text { clinical arteriongraphy } \\
\text { indications }\end{array}$ \\
\hline
\end{tabular}

HC, hospital controls; PC, healthy population controls.

Table 2. The association between periodontal disease and CHD risk among Chinese. 


\begin{tabular}{|c|c|c|c|c|}
\hline Analysis model & $\mathrm{n}$ & $\mathrm{ORr}(95 \% \mathrm{Cl})$ & ORf(95\%Cl) & $\mathrm{P}_{\mathrm{h}}$ \\
\hline Total analysis & 15 & $3.04(2.37-3.92)$ & $2.74(2.40-3.12)$ & 0.000 \\
\hline \multicolumn{5}{|l|}{ Geographic areas } \\
\hline South China & 7 & 3.89 (2.38-6.35) & $2.81(2.31-3.41)$ & 0.000 \\
\hline North China & 8 & $2.66(2.03-3.49)$ & $2.68(2.25-3.19)$ & 0.032 \\
\hline \multicolumn{5}{|l|}{ Control sources } \\
\hline Healthy population controls & 4 & $4.08(2.18-7.64)$ & $3.52(2.70-4.58)$ & 0.002 \\
\hline Hospital controls & 11 & $2.75(2.10-3.58)$ & $2.52(2.17-$ & 0.002 \\
\hline \multicolumn{5}{|l|}{ Dental assessment method } \\
\hline attachment loss & 3 & $3.86(1.74-8.56)$ & $3.10(2.29-4.1 \mathrm{c}$ & 0.012 \\
\hline periodontal index & 5 & $2.75(1.82-4.17)$ & $2.60(2.11-3.19)$ & 0.007 \\
\hline two or more clinical indications & 2 & $2.55(1.77-3.66)$ & $2.55(1.78-3.67)$ & 0.481 \\
\hline gum recession & 3 & 3.49 (1.47-8.27) & $2.82(2.10-3.78)$ & 0.001 \\
\hline alveolar bone loss & 2 & $4.24(0.93-19.21)$ & & 0.008 \\
\hline \multicolumn{5}{|l|}{ CHD assessment method } \\
\hline WHO criteria & 4 & $3.74(1.87-7.46)$ & $3.01(2.20-4.12)$ & 0.009 \\
\hline coronary arteriongraphy & 10 & $3.08(2.27-4.19)$ & $2.85(2.44-3.33)$ & 0.000 \\
\hline
\end{tabular}

ORr: Odd ratio for random-effects model; ORf: Odd ratio for fixed-effects model; $\mathrm{P}_{\mathrm{h}}$ : $P$ value for heterogeneity test.

\section{Figures}

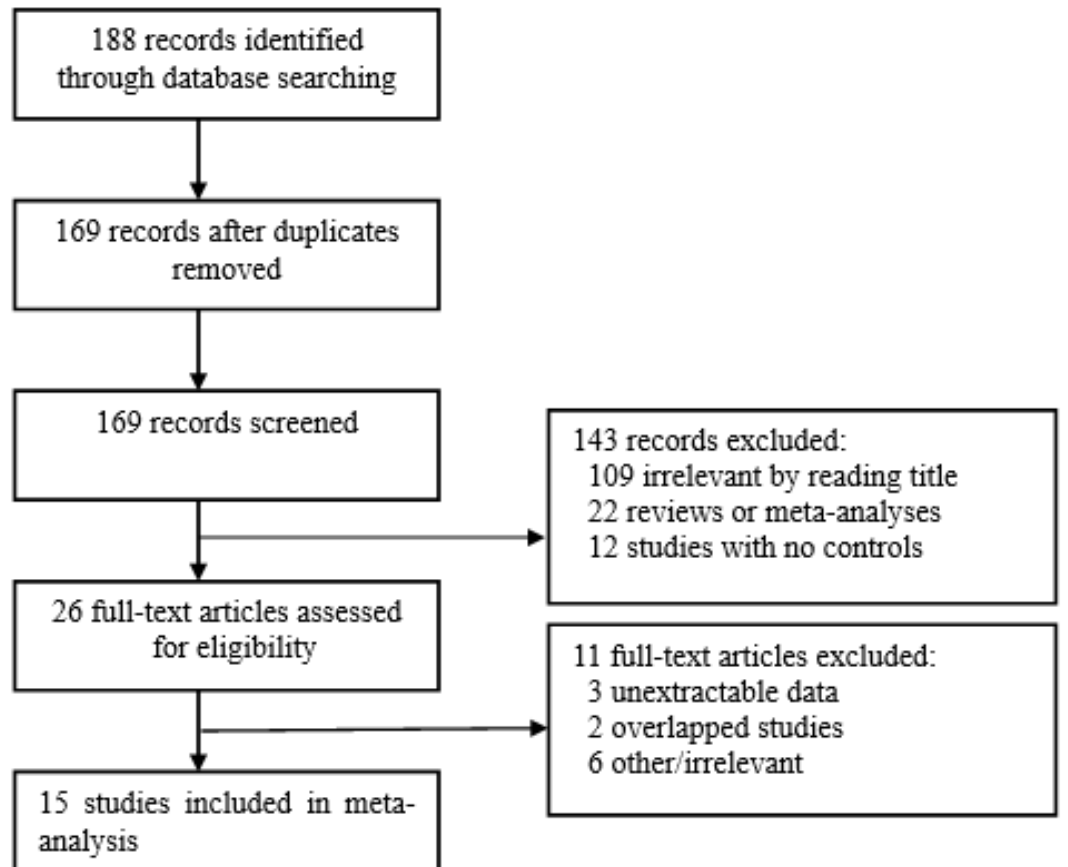

Figure 1

Flow diagram of the literature search. 
Study

ID
OR $(95 \% \mathrm{Cl})$
$\%$

Weight

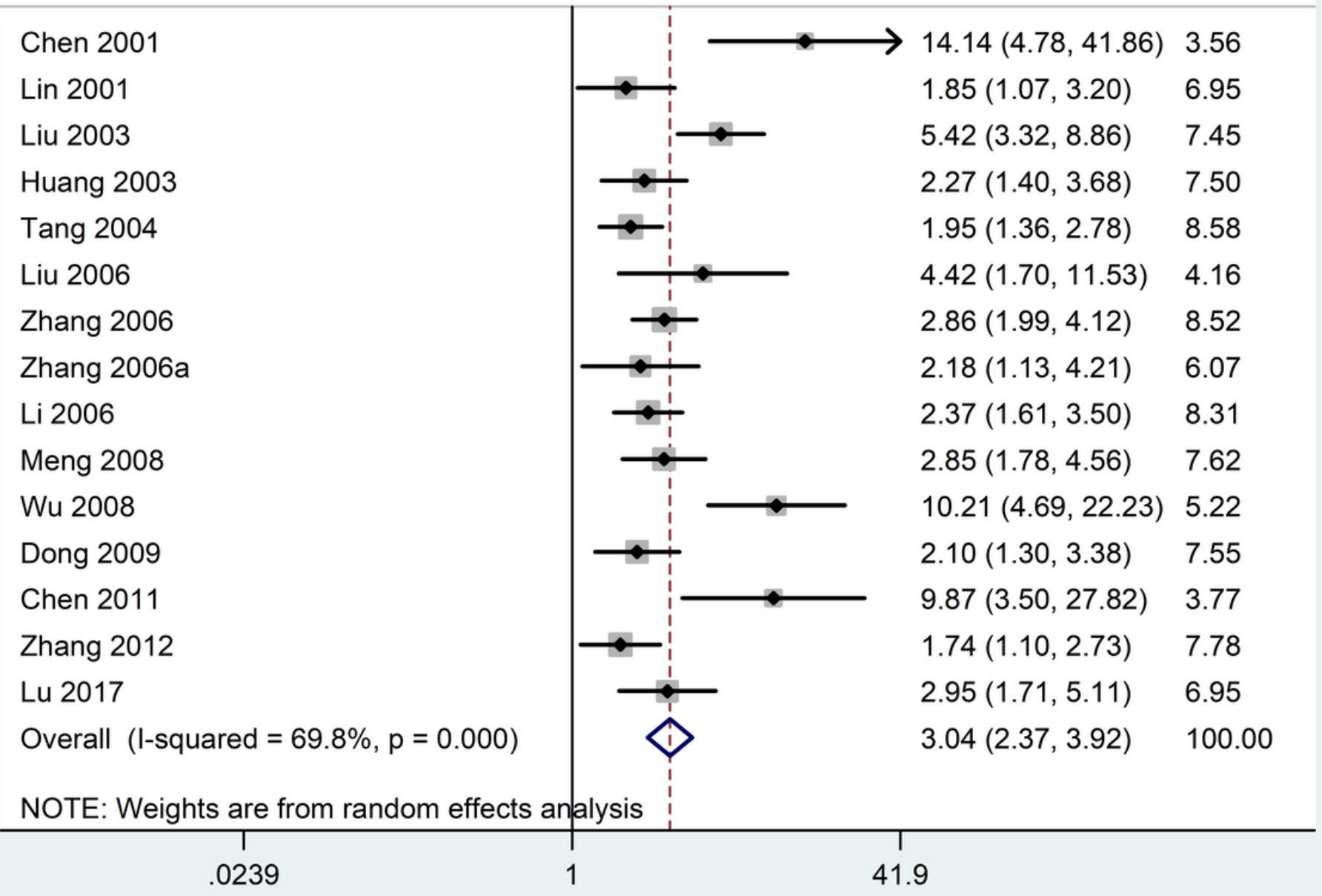

Figure 2

The forest plot on the association between periodontal disease and CHD risk in total analysis. 


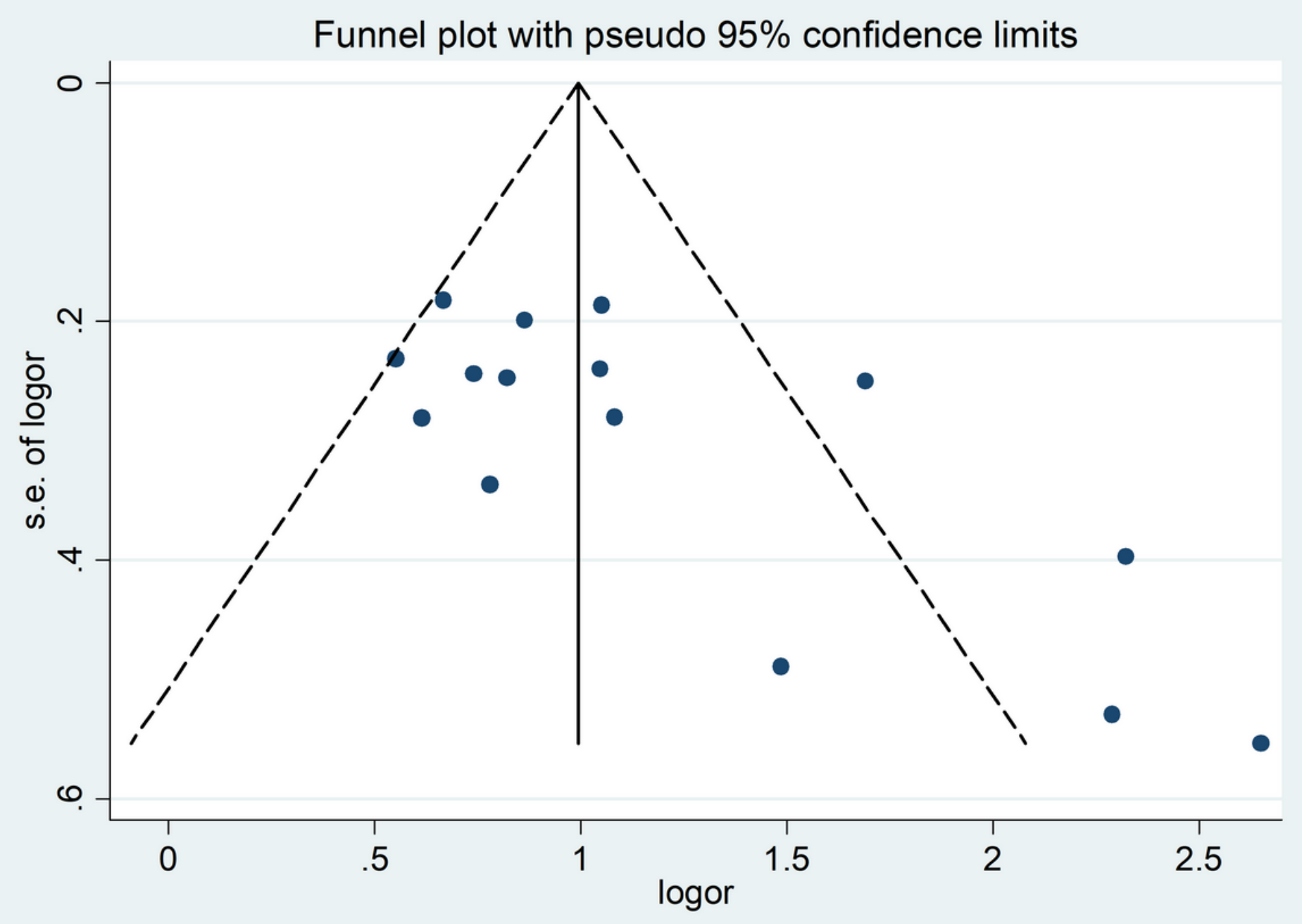

Figure 3

Publication bias assessment using Begg's funnel plot. 


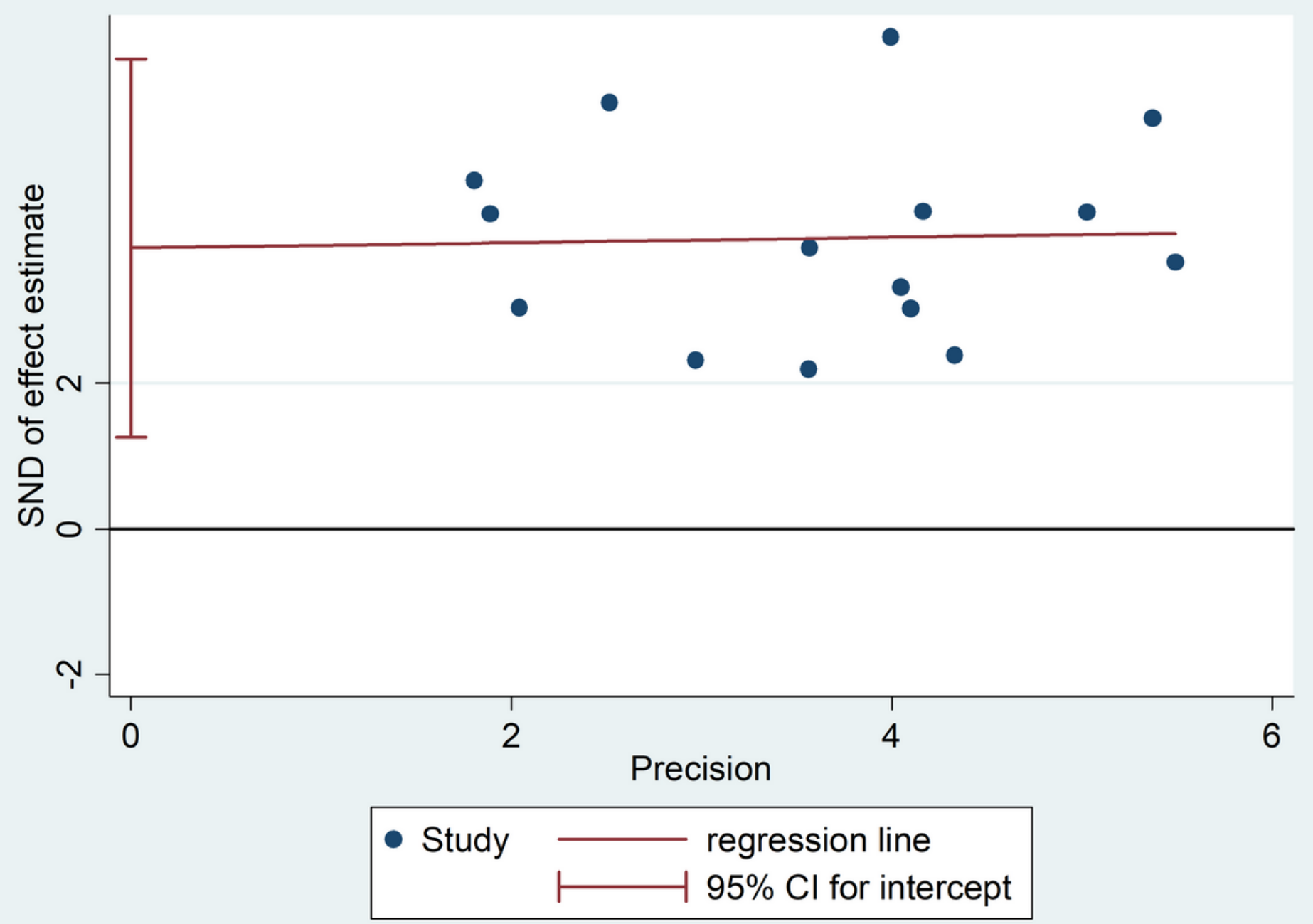

Figure 4

Egger's linear regression. 